\title{
Impact of the Atlantic Multidecadal Oscillation (AMO) on deriving anthropogenic warming rates from the instrumental temperature record
}

\author{
G. R. van der Werf and A. J. Dolman \\ VU University Amsterdam, Faculty of Earth and Life Sciences, Amsterdam, the Netherlands \\ Correspondence to: G. R. van der Werf (guido.vander.werf@vu.nl) \\ Received: 16 April 2014 - Published in Earth Syst. Dynam. Discuss.: 8 May 2014 \\ Revised: 29 August 2014 - Accepted: 18 September 2014 - Published: 30 October 2014
}

\begin{abstract}
The instrumental surface air temperature record has been used in several statistical studies to assess the relative role of natural and anthropogenic drivers of climate change. The results of those studies varied considerably, with anthropogenic temperature trends over the past 25-30 years suggested to range from 0.07 to $0.20^{\circ} \mathrm{C}$ decade $^{-1}$. In this short communication, we assess the origin of these differences and highlight the inverse relation between the temperature trend of the past 30 years and the weight given to the Atlantic Multidecadal Oscillation (AMO) as an explanatory factor in the multiple linear regression (MLR) tool that is usually employed. We highlight that robust MLR outcomes require a better understanding of the AMO in general and, more specifically, of its characterization. Our results indicate that both the high and the low end of the anthropogenic trend over the past 30 years found in previous studies are unlikely and that a transient climate response of $1.6(1.0-3.3)^{\circ} \mathrm{C}$ best captures the historic instrumental temperature record.
\end{abstract}

\section{Introduction}

The surface air temperature of the earth is influenced by a large number of natural and anthropogenic factors (Bindoff et al., 2013). The relative role of these has been the subject of much debate, both in the scientific community and in the public domain. Climate models rooted in physics are the preferred tool for performing attribution studies and project future climate but have difficulty in predicting variability related to natural processes such as the El Niño-Southern Oscillation (ENSO). Simple statistical models have therefore also been used to explain the evolution of the temperature record (Foster and Rahmstorf, 2011; Lean and Rind, 2008; Santer et al., 2001; Tung and Zhou, 2013)

Most of these studies used a multiple linear regression (MLR), where a dependent variable (in this case, temperature) is explained by a number of explanatory variables, using covariations in the dependent and explanatory variables. One recent outcome, highlighted by Zhou and Tung (2013) and Chylek et al. (2014), is that the residuals of an MLR exercise using anthropogenic forcing, solar radiation, volcanic activity, and ENSO as explanatory variables correlates strongly with the Atlantic Multidecadal Oscillation (AMO) (see Fig. 1). Including the AMO in an MLR therefore increased the correlation with observed global temperature. The AMO has been in a warming mode since about 1980, so it "competes" with anthropogenic forcings to explain the warming since then (DelSole et al., 2011). The implications are that, depending on whether or not the AMO was included, the calculated anthropogenic warming rate of the recent 25-30-year period varied considerably between $0.07 \mathrm{~K} \mathrm{decade}^{-1}$ (Zhou and Tung, 2013) and $0.20 \mathrm{~K} \mathrm{decade}^{-1}$ (Lean and Rind, 2008), although the time periods considered do not overlap completely.

The term AMO was introduced by Kerr (2000), but the oscillation was identified earlier (Bjerknes, 1964; Schlesinger and Ramankutty, 1994). Variability in the AMO has been traced back in the instrumental record to over 350 years ago (Tung and Zhou, 2013) and, using different types of proxy data, up to 8000 years ago (Chylek et al., 2012; Delworth and Mann, 2000; Knudsen et al., 2011). However, Booth et al. (2012) argued that, since 1860, the AMO has been for the 

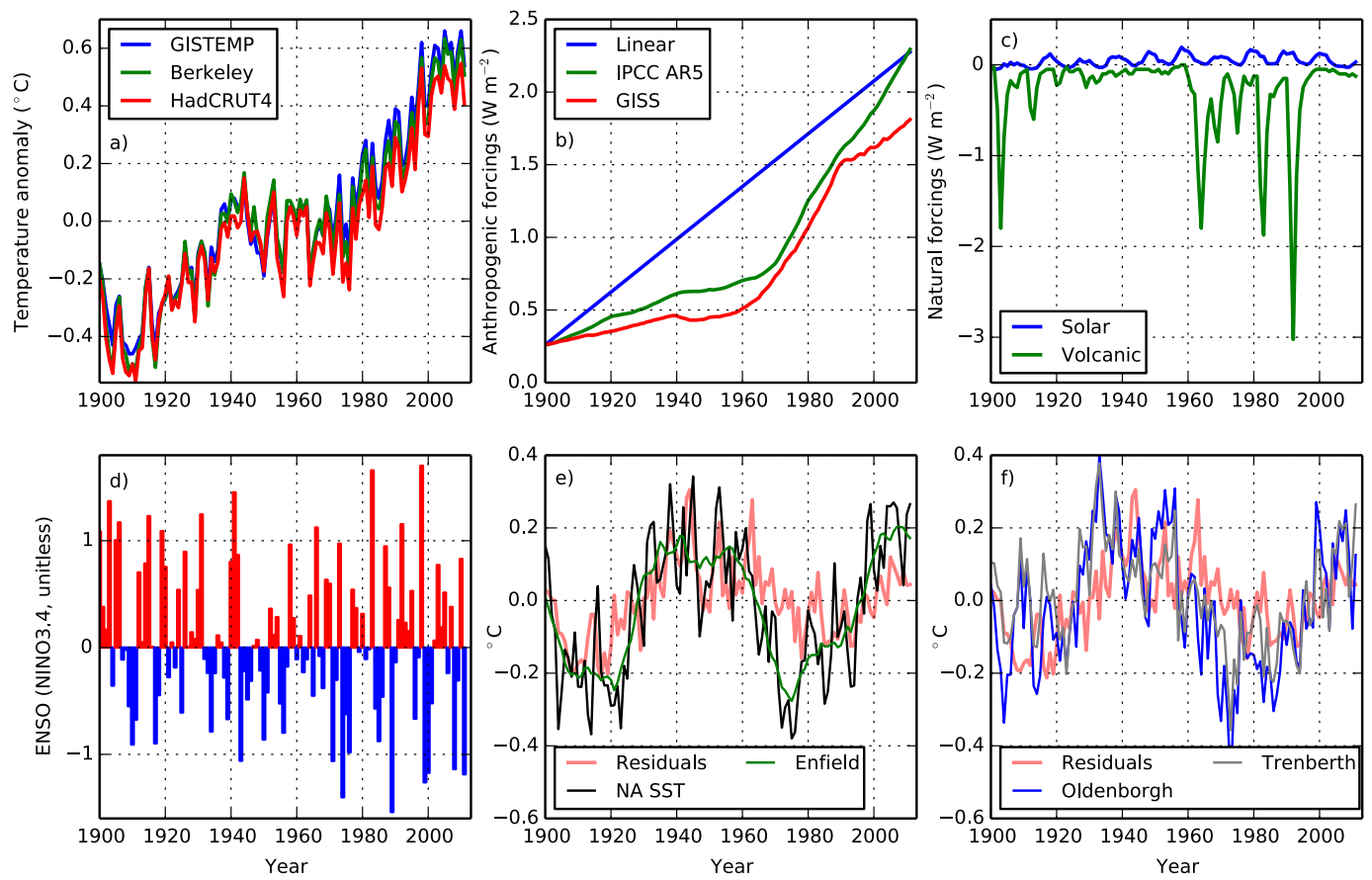

Figure 1. Input data sets used in this study: (a) three different temperature data sets, (b) anthropogenic forcings, (c) solar and volcanic forcings, (d) ENSO, (e) AMO characterizations based only on NA SST, and (f) AMO characterizations aiming to isolate the intrinsic AMO signal. Also shown in (e) and (f) are MLR residuals when explaining GISTEMP temperature with GISS anthropogenic radiative forcing as well as with solar and volcanic forcings, and volcanoes, and ENSO as explanatory variables.

most part related to changes in aerosol loads driven mostly by anthropogenic emissions. These two lines of thought (natural versus anthropogenic) are difficult to reconcile. However, given the multiple lines of evidence showing a natural component and doubts on whether aerosols are indeed driving the AMO (Zhang et al., 2013), we assume here that the AMO represents a natural oscillation.

The uncertain nature of this oceanic oscillation and its teleconnections makes it difficult to characterize the AMO for use in MLR studies. In its simplest form the AMO is based on the North Atlantic sea surface temperature (NA SST) but linearly detrended to compensate for anthropogenic warming. This is also the characterization used in the MLR studies of Zhou and Tung (2013) and Chylek et al. (2014). However, the NA SST itself is influenced by short-term variability, such as volcanic activity and ENSO. Enfield et al. (2001) therefore proposed using a 10-year running mean of the detrended NA SST. Going one step further and also aiming to account for nonlinearities in detrending the NA SST, Van Oldenborgh et al. (2009) computed an AMO index based on the averaged SST in the North Atlantic minus the regression of this SST on global mean temperature. This approach supersedes that of Trenberth and Shea (2006), which includes more influence of the tropical regions. These four AMO characterizations are shown in Fig. 1e and f. This short communication aims to identify how important these different characterizations of the AMO, as well as the shape of the anthropogenic influence, are for the outcomes of MLR studies and derived estimates of the transient climate response (TCR).

\section{Data and methods}

We repeated the analyses of Chylek et al. (2014) and Zhou and Tung (2013), where the global temperature pattern is described using MLR by five factors: anthropogenic, solar, volcanic, ENSO and AMO (Fig. 1). We systematically altered the characterization of the AMO (no AMO or four different descriptions; Fig. 1e and f) and the anthropogenic influence: linear as in Zhou and Tung (2013), or based on the radiative forcing as in Chylek et al. (2014), for a total of 10 MLR runs.

We focused on the 1900-2011 period and used the Intergovernmental Panel on Climate Change (IPCC) fifth assessment report (AR5) radiative forcing estimates (Myhre et al., 2013). Net IPCC AR5 forcing estimates are higher and have a somewhat different pattern than the Goddard Institute for Space Studies (GISS) anthropogenic forcings from Hansen et al. (2011; http://data.giss.nasa.gov/modelforce/Fe. 1880-2011.txt) used in Chylek et al. (2014) and in the discussion version of this paper (Fig. 1b). The increase in net forcing is mostly due to reduced (less negative) estimates of the aerosol forcings. Our main analyses relied on GISS global average annual temperature (GISTEMP) available at http://data.giss.nasa.gov/gistemp/Temperature (Hansen et al., 2010). We tested the sensitivity of our results to using 
global average temperature estimates of (1) the blended Met Office Hadley Centre and the Climatic Research Unit at the University of East Anglia HadCRUT4 (Morice et al., 2012) and (2) the Berkeley Earth Surface Temperature Study (Rohde et al., 2013) (see Fig. 1a). One key difference between the temperature data sets is that HadCRUT4 does not extrapolate beyond station data in the rapidly warming Arctic region, and its trend is thus somewhat lower than the other two data sets, which do extrapolate here (Fig. 1a).

ENSO was based on Kaplan et al. (1998), available from http://climexp.knmi.nl/data/inino5.dat. All oceanic factors (AMO and ENSO) were based on annual means with a 6month delay that was chosen because it yielded highest correlations. Solar radiation and volcanic activity were taken from the IPCC AR5 forcings mentioned above. This setup is similar to the one used in Chylek et al. (2014), except that we used an updated radiative forcing data set and a more frequently used ENSO parameterization. Zhou and Tung (2013) analyzed a longer time period (1856-2012), but, given the limited spatial coverage of the temperature data set for the 19th century, we refrain from extending our study period to before 1900. Another key difference compared to Chylek et al. (2014) is that Zhou and Tung (2013) did not use the anthropogenic forcings but a linear trend, just as Foster and Rahmstorf (2011) did. However, the latter study focused on a much shorter time period than the former.

We performed 10 MLR runs on an annual time step over 1900-2011; the first 5 runs were based on a linear trend for the anthropogenic factor as in Foster and Rahmstorf (2011) and Zhou and Tung (2013), the second 5 with the anthropogenic radiative forcing for the anthropogenic factor as in Lean and Rind (2008) and Chylek et al. (2014) but with updated data. The linear trend we used had the same overall slope as the anthropogenic radiative forcing time series so that their coefficients in the MLR could be compared. Within these two sets of five scenarios we only changed how the AMO was represented; (i) no AMO, (ii) AMO based on the detrended NA SST, (iii) as (ii) but with a 10year running mean as in Enfield et al. (2001), (iv) as in Van Oldenborgh et al. (2009), and (v) as in Trenberth and Shea (2006). The AMO descriptions of Van Oldenborgh et al. (2009) and Trenberth and Shea (2006) are specifically designed to isolate the AMO signal from external factors. The four different AMO characterizations will be referred to as "NA SST", "Enfield", "Van Oldenborgh", and "Trenberth" and are shown in Fig. 1e and $\mathrm{f}$.

We used the outcomes of the MLR exercises (always for the whole 1900-2011 study period) to estimate the anthropogenic temperature trend over the past 30, 60, and 100 years. These trends were established by fitting a linear trend to the observed temperature, with natural factors subtracted. The latter were based on the MLR regression coefficient multiplied by the observed pattern for each of the four factors analyzed here (solar, volcanic, ENSO, and AMO). Finally, to estimate the TCR, the MLR regression coefficients for the anthropogenic forcing estimates were multiplied by $3.71 \mathrm{~W} \mathrm{~m}^{-2}$ (the radiative forcing of a $\mathrm{CO}_{2}$ doubling). To estimate its uncertainty, we carried out a Monte Carlo simulation accounting for uncertainties in the radiative forcing estimates based on Myhre et al. (2013), uncertainty in the MLR regression coefficient, and uncertainties from and between the temperature time series. Because the GISTEMP data set has no uncertainty estimates, we used those from the relatively similar Berkeley temperature data set. Uncertainties reported throughout this paper are 5th and 95th percentiles.

\section{Results}

The regression coefficients for the anthropogenic factor (Fig. 2a) varied little between the 10 different runs, indicating that the role of anthropogenic forcing is relatively robust in these MLRs. For solar radiation the coefficient was negative when the anthropogenic influence in the MLR was represented by a linear trend, while it had a roughly similar (which was expected) or somewhat higher value than the anthropogenic factor when this influence was based on the anthropogenic radiative forcings (Fig. 2b). The variability in coefficients for volcanic and ENSO influences (Fig. 2c and d) were fairly comparable, with the most weight given to these factors when running without AMO and the least weight when using the NA SST, and intermediate weight when using one of the other AMO descriptions. The coefficients for volcanoes and ENSO were relatively insensitive to the shape of the anthropogenic factor.

The coefficients for the AMO (Fig. 2e) varied considerably between the four characterizations, with those based on the NA SST having the highest coefficients. Between these two, using 10-year running mean values (Enfield et al., 2001) resulted in a somewhat higher coefficient than the plain annual detrended NA SST. The coefficients for the more intrinsic AMO characterizations were lower, especially when the anthropogenic factor was represented by the anthropogenic forcing instead of a linear trend. As shown earlier by Chylek et al. (2014), highest coefficients of determination are achieved when using the NA SST as a proxy for AMO (Fig. 2f), with the annual data having a marginally higher coefficient of determination than the 10-year running mean. The other AMO parameterizations also boosted correlation compared to running without AMO but to a smaller degree. These coefficients of determination were adjusted for the number of explanatory variables, which was four for the runs without AMO and five when running with AMO.

Finally, the long-term rate of anthropogenic warming for both the 100 and 60-year period varied little between the MLRs and all indicated an acceleration when going from a 100 -year to a 60-year period (Fig. $2 \mathrm{~g}$ and h). These time periods are somewhat arbitrary, but results were very similar when investigating a 70- or 50-year period instead of 60 years. Results varied much more for what is the shortest 

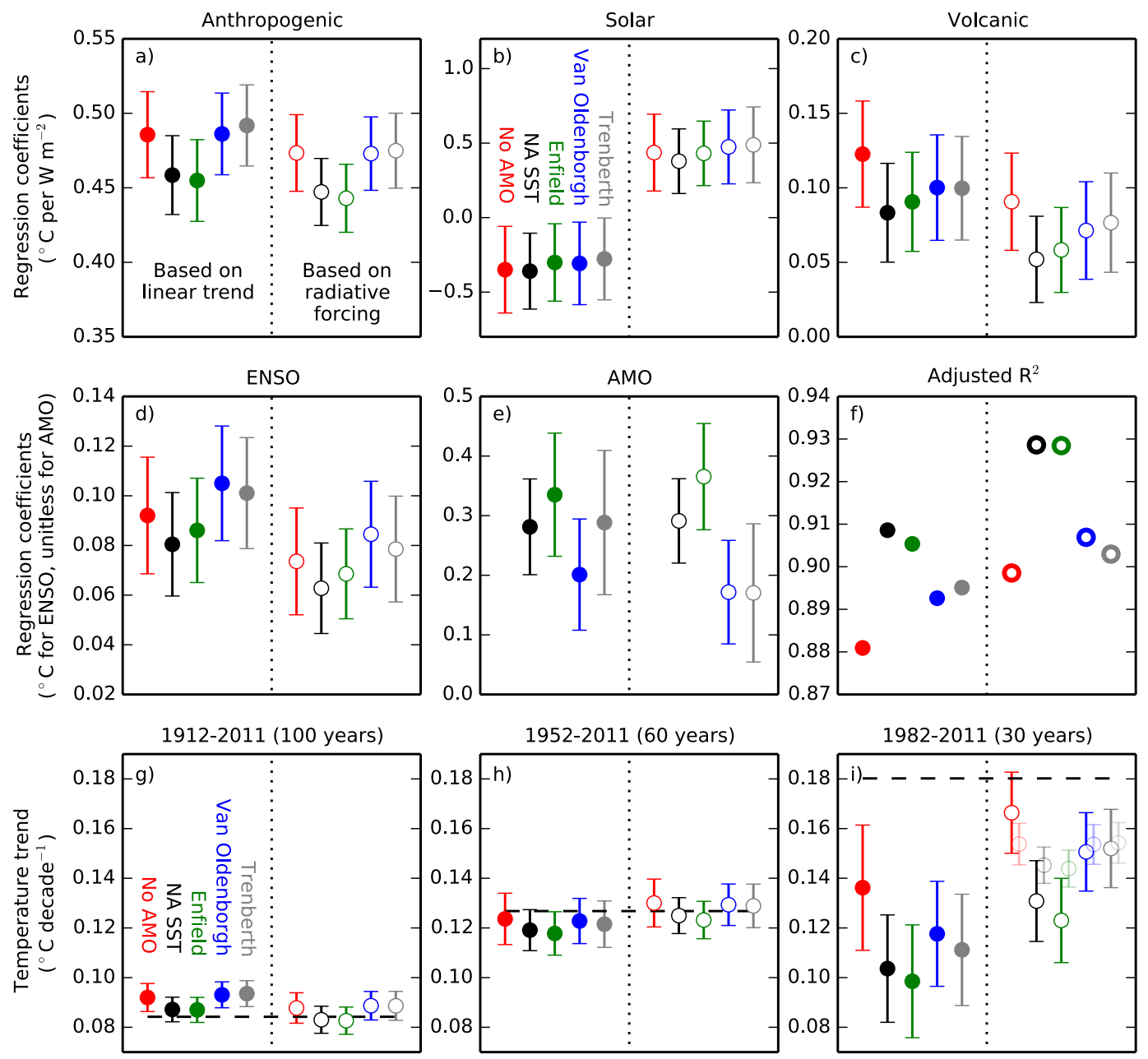

Figure 2. Regression coefficients (a-e), adjusted coefficient of determination (f), and calculated anthropogenic trends as well as observed temperature trends (dotted black lines) for three different time windows (g-i) for MLR exercises over the 1900-2011 period using GISTEMP temperature data. Light-colored bars in (i) are calculated anthropogenic temperate trends based on the regression coefficients shown in (a) and the change in forcing. Results are shown for 10 different MLR exercises, with the first five (closed circles) based on a linear trend for the anthropogenic influence and the second five (open circles) using IPCC AR5 anthropogenic radiative forcing instead. Within these two sets, five MLRs were done: one without AMO and four with different AMO descriptions as indicated in (b) and (g). Error bars indicate 5 and 95 percentiles, without taking uncertainties in input data sets into account.

time interval when investigating climate (30 years), as shown in Fig. 2i. These results were inversely related to the weight given to the AMO (shown in Fig. 3 for the anthropogenicradiative-forcing-based estimates) and yielded the highest values when excluding the AMO and lowest values with AMO as characterized by Enfield et al. (2001). However, the key result here is that intermediate values are also possible; the characterization of the AMO as well as the temperature data set used played an important role (Fig. 3). According to our results, anthropogenic temperature trends for the past 30 years were between about 0.11 and $0.17^{\circ} \mathrm{C}$ per decade (Fig. 2i; range of values based on using radiative forcing as anthropogenic influence and including AMO). The anthropogenic trends calculated in this way show a similar pattern as and agree within their uncertainties with the trends we had expected from multiplying the coefficients found for the anthropogenic forcing (Fig. 2a) with the change in forcing over the 1982-2011 period $\left(1.01 \mathrm{~W} \mathrm{~m}^{-2}\right)$, shown in light colors in Fig. 2i. However, the difference is larger than expected for the NA SST and Enfield AMO descriptions, potentially reflecting nonlinearities or temporal variability in the impact of natural forcings and, in general, highlighting uncertainties in these approaches.

To some degree, a similar way of how AMO characterizations influenced the 30-year anthropogenic warming rate was seen in the TCR values we derived from multiplying the coefficients given to the anthropogenic factor with the radiative forcing of a $\mathrm{CO}_{2}$ doubling (Table 1). In general, 
Table 1. Transient climate response (TCR, in ${ }^{\circ} \mathrm{C}$ ) including 5 th and 95 th percentiles based on Monte Carlo simulations taking into account uncertainties in radiative forcing, its regression coefficient, and temperature data.

\begin{tabular}{lcccc}
\hline \multirow{2}{*}{ AMO description } & \multicolumn{4}{c}{ Temperature data set } \\
\cline { 2 - 5 } & GISTEMP & HadCRUT4 & Berkeley & All \\
\hline No AMO & $1.76(1.16-3.55)$ & $1.57(1.03-3.18)$ & $1.67(1.10-3.38)$ & $1.67(1.09-3.37)$ \\
NA SST & $1.66(1.09-3.34)$ & $1.46(0.96-2.95)$ & $1.55(1.02-3.13)$ & $1.56(1.01-3.16)$ \\
Enfield & $1.64(1.08-3.32)$ & $1.43(0.94-2.89)$ & $1.52(1.00-3.08)$ & $1.53(0.99-3.11)$ \\
Van Oldenborgh & $1.75(1.16-3.55)$ & $1.57(1.03-3.17)$ & $1.67(1.10-3.37)$ & $1.66(1.09-3.36)$ \\
Trenberth & $1.76(1.16-3.56)$ & $1.58(1.04-3.20)$ & $1.68(1.11-3.38)$ & $1.67(1.09-3.39)$ \\
\hline All* & $1.70(1.12-3.44)$ & $1.51(0.98-3.06)$ & $1.61(1.05-3.26)$ & $1.61(1.04-3.26)$ \\
\hline
\end{tabular}

* "No AMO" runs excluded.

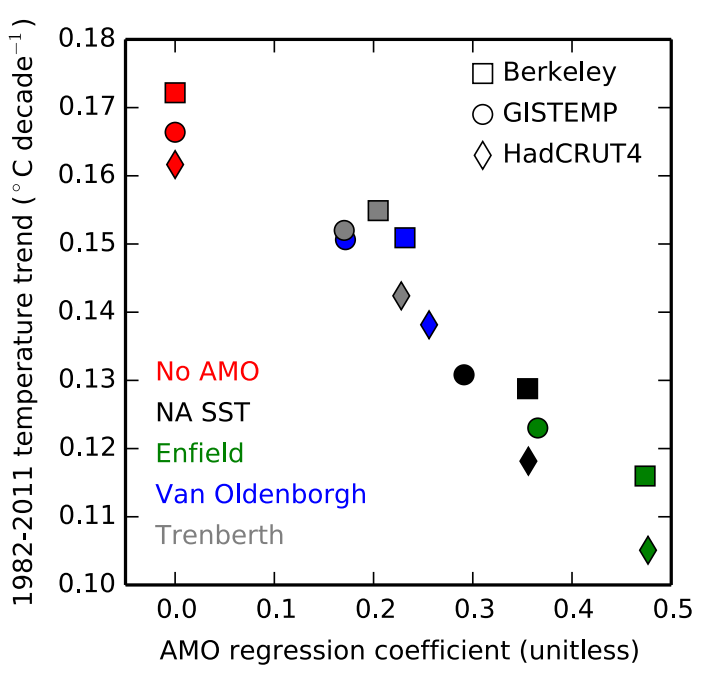

Figure 3. Relation between the weight given to the AMO in the MLR and the derived anthropogenic temperature trend over 19822011 for three different temperature data sets and five different AMO characterizations.

including AMO lowered the TCR, but to a much smaller degree than for the 30-year anthropogenic warming rate discussed above. This is because of the longer time period considered (1900-2011) and the thus smaller relative impact of multidecadal oscillations. Differences in temperature data sets had a larger impact on the calculated TCRs than the different AMO description, with GISTEMP and Berkeley generally being higher than results based on HadCRUT4. When randomly choosing the temperature data set and AMO description (excluding running without AMO) in the Monte Carlo simulation, TCR was found to be $1.6(1.0-3.3)^{\circ} \mathrm{C}$ (Table 1).

\section{Discussion}

The different MLRs pointed out that the choice of AMO and anthropogenic representation substantially impacts the results of these exercises. The weight given to the anthropogenic influence and thus the derived TCR, however, was quantitatively remarkably robust between the scenarios. These two main findings are discussed in more detail below.

There was one crucial difference between the scenarios that were based on a linear anthropogenic trend versus those based on the anthropogenic forcing: the former indicated a negative impact of solar radiation. When considering an earlier start year (1856), as done in Zhou and Tung (2013), the coefficient becomes positive but not statistically different from 0 . The underlying reason for this small - or even negative - effect is that the warming rate in the 1910-1940 and 1970-2000 periods was relatively similar and is thus best captured by a linear function, leaving no room for solar radiation, which increased during the early 20th-century warming to explain part of the signal. The radiative forcing signal, however, has a smaller slope during the early 20thcentury warming than during the late 20th-century warming, thus requiring solar radiation to have an influence because it increased in strength during the early 20th-century warming but not during the late warming.

Since (1) the shape of the anthropogenic forcing is known to be nonlinear (while large uncertainties exist in the aerosol forcing, the dominant greenhouse gas forcing is well known and increased exponentially) and (2) it is almost certainly a statistical artefact that the measured variability in solar radiation has a negative or no influence, we feel it is more justifiable to use the anthropogenic forcing as the predefined shape of the anthropogenic influence. A consequence is that part of the recent air temperature plateau can be explained by a lull in solar activity over the past decade; see for example Schmidt et al. (2014) and discussion therein. Our work also highlights the role of ENSO and stagnating AMO in this. In the work where a linear trend for the anthropogenic factor was used (Tung and Zhou, 2013; Zhou and Tung, 2013), it is acknowledged that not too much weight should be given to the results for the solar coefficients, indicating again that using the radiative forcing is the preferred way to go forward. Studies using a linear trend for the anthropogenic forcing 
yielded the lowest anthropogenic temperature trend for the past 30 years $\left(0.07^{\circ} \mathrm{C}\right.$ decade $\left.^{-1}\right)$, which is partly an artefact of using a linear trend but also related to using a very early start year. One other reason for not making the linear trend assumption is that this yields lower correlations (Fig. 2f), although we shall see below that this should not be the sole criterion for choosing representations. For the rest of the discussion we therefore focus on the results derived from using radiative forcing to describe the anthropogenic factor (the open circles in Fig. 2).

The inverse relation between the weight given to the AMO and the 30-year anthropogenic trend as shown in Fig. 3 begs the question which AMO description is most accurate. But first, we iterate on the implications drawn from the different MLRs. The temperature amplitude of the AMO is about $0.4^{\circ} \mathrm{C}$, and the AMO regression coefficient indicates what fraction of that $0.4^{\circ} \mathrm{C}$ is maintained in the global temperature record. The NA covers about $10 \%$ of the global earth surface, and the bare minimum coefficient should therefore be about 0.1 , but it is probably higher because of impacts of the NA SST on surrounding land surface and due to teleconnections (Chylek et al., 2009; Knight et al., 2006) and potentially due to positive land surface feedbacks (Della-Marta et al., 2007). Studies that did not include the AMO (Foster and Rahmstorf, 2011; Lean and Rind, 2008) will therefore yield anthropogenic trends that are too high during periods when the AMO transitions from a cool to a warm phase, as happened over the past 30-40 years.

The maximum coefficient indicated by the various scenarios is about 0.5 (Fig. 3), which would indicate strong teleconnections because the AMO effect would be felt over half of the earth's surface, for example as a result of modifying cloud patterns. Where in between the $\sim 0.1$ and $\sim 0.5$ the coefficient should lie is speculation and depends for the most part on our ability to better understand and characterize the AMO and its teleconnections. The results are sensitive to whether the AMO peaks higher during the current than the previous cycle (as indicated by the detrended annual and running mean NA SST) or not (as indicated by Van Oldenborgh et al., 2009, and Trenberth and Shea, 2006) (see Fig. 1e and f). We argue that using the straight detrended NA SST (Chylek et al., 2014; Zhou and Tung, 2013) is not the preferred approach because it is contaminated by external factors and potentially gives more weight to the AMO at the expense of, for example, volcanoes and ENSO (Fig. 2), even though it yields the highest correlation. However, when partly accounting for this by using a 10-year running mean, the results with regard to the weight given to AMO, and thus the anthropogenic temperature trend of the past 30 years, do not deviate much from when annual data are used. In fact, the AMO coefficient increased somewhat, and the coefficients for ENSO and volcanoes were more in line with the other MLRs, although still lower. Only when using more sophisticated approaches for the AMO did the coefficient drop substantially and increased the calculated anthropogenic warming trend for the past 30 years.

One other outcome of these MLR analyses is that most of the temperature increase over the past 100 years was of anthropogenic origin, whether the AMO was included or not and whether the anthropogenic shape was linear or followed the forcing estimates. This indicates that there is no combination of natural factors considered here that could better match the observed temperature pattern than one with a large anthropogenic influence. This translates to relatively stable TCR values that differed more due to changing temperature data sets than due to differences in AMO characterization (Table 1). Our values were somewhat higher but well within the uncertainty range of recent studies based on energy budget constraints, e.g., Otto et al. (2013), but lower than more sophisticated attribution studies also accounting for the spatial variability (e.g., Stott et al., 2006). Key advantages of the MLR approach over energy budget studies are that we can account for the temporal patterns and that the MLR may better isolate the anthropogenic signal from the natural signal.

\section{Conclusions}

Assuming that at least part of the AMO is of natural origin and given that it has a substantial temperature cycle and large footprint, it should be included in MLR studies as an explanatory variable. This will lower the anthropogenic temperature trend for the past 30 years compared to MLR studies neglecting the AMO, as shown by Zhou and Tung (2013) and Chylek et al. (2014). However, our results indicate that the degree to which this is the case depends on the choice of AMO description. Using detrended NA SST indicates a strong role for the AMO and thus a relatively low anthropogenic warming trend for the past 30 years, but these observations are contaminated by other factors influencing NA SST. More sophisticated AMO descriptions indicate a similar or smaller role for the AMO, and consequently potentially higher anthropogenic warming trends, for the past 30 years. Our results thus imply that a better understanding of the AMO is required to increase our confidence in the outcomes of these MLR exercises, especially when considering relatively short periods when fluctuations in multidecadal oscillations such as the AMO do not average out.

The most robust outcome of the different MLRs we ran was the anthropogenic factor, which indicated a transient climate response (TCR) of $1.6(1.0-3.3){ }^{\circ} \mathrm{C}$, with the uncertainty range reflecting uncertainties in AMO characterization as well as the temperature and radiative forcing data sets used. These values are somewhat higher but well within the uncertainty range of recent studies based on energy budget constraints. The added benefit from an MLR approach is that it takes the temporal signal into account and may better isolate the anthropogenic factor from natural variability. 
Acknowledgements. We would like to thank two reviewers for their constructive suggestions; Nicholas Lewis, Jos Hagelaars, Marcel Crok, and Rob Dekker for their helpful comments on an earlier version of this paper; all data providers for sharing their results publicly; and Geert Jan van Oldenborgh for maintaining the Climate Explorer at KNMI. This work was supported by the European Research Council (ERC), grant number 280061. Python code and data used for the analyses can be derived from http://www.falw.vu/ gwerf/code/MLR_AMO_TCR/.

Edited by: G. Lohmann

\section{References}

Bindoff, N. L., Stott, P. A., AchutaRao, K. M., Allen, M. R., Gillett, N., Gutzler, D., Hansingo, K., Hegerl, G., Hu, Y., Jain, S., Mokhov, I. I., Overland, J., Perlwitz, J., Sebbari, R., and Zhang, X.: Detection and Attribution of Climate Change: from Global to Regional, in: Climate Change 2013: The Physical Science Basis, Contribution of Working Group I to the Fifth Assessment Report of the Intergovernmental Panel on Climate Change, edited by: Stocker, T. F., Qin, D., Plattner, G. K., Tignor, M., Allen, S. K., Doschung, J., Nauels, A., Xia, Y., Bex, V., and Midgley, P. M., Cambridge University Press, 867-952, 2013.

Bjerknes, J.: Atlantic Air-Sea Interaction, Adv. Geophys., 10, 1-82, 1964.

Booth, B. B. B., Dunstone, N. J., Halloran, P. R., Andrews, T., and Bellouin, N.: Aerosols implicated as a prime driver of twentiethcentury North Atlantic climate variability, Nature, 484, 7393, doi:10.1038/nature10946, 2012.

Chylek, P., Folland, C. K., Lesins, G., Dubey, M. K., and Wang, M.: Arctic air temperature change amplification and the Atlantic Multidecadal Oscillation, Geophys. Res. Lett., 36, L14801, doi:10.1029/2009GL038777, 2009.

Chylek, P., Folland, C., Frankcombe, L., Dijkstra, H., Lesins, G., and Dubey, M.: Greenland ice core evidence for spatial and temporal variability of the Atlantic Multidecadal Oscillation, Geophys. Res. Lett., 39, L09705, doi:10.1029/2012GL051241, 2012.

Chylek, P., Klett, J. D., Lesins, G., Dubey, M. K., and Hengartner, N.: The Atlantic Multidecadal Oscillation as a dominant factor of oceanic influence on climate, Geophys. Res. Lett., 41, 1-9, doi:10.1002/2014GL059274, 2014.

Della-Marta, P. M., Luterbacher, J., von Weissenfluh, H., Xoplaki, E., Brunet, M., and Wanner, H.: Summer heat waves over western Europe 1880-2003, their relationship to large-scale forcings and predictability, Clim. Dynam., 29, 251-275, doi:10.1007/s00382007-0233-1, 2007.

DelSole, T., Tippett, M. K., and Shukla, J.: A significant component of unforced multidecadal variability in the recent acceleration of global warming, J. Climate, 24, 909-926, doi:10.1175/2010JCLI3659.1, 2011.

Delworth, T. L. and Mann, M. E.: Observed and simulated multidecadal variability in the Northern Hemisphere, Clim. Dynam., 16, 661-676, 2000.

Enfield, D. B., Mestas-Nunez, A. M., and Trimble, P. J.: The Atlantic multidecadal oscillation and its relation to rainfall and river flows in the continental US, Geophys. Res. Lett., 28, 2077-2080, 2001.
Foster, G. and Rahmstorf, S.: Global temperature evolution 1979-2010, Environ. Res. Lett., 6, 044022, doi:10.1088/17489326/6/4/044022, 2011.

Hansen, J., Ruedy, R., Sato, M., and Lo, K.: Global surface temperature change, Rev. Geophys., 48, RG4004, doi:10.1029/2010RG000345, 2010.

Hansen, J., Sato, M., Kharecha, P., and von Schuckmann, K.: Earth's energy imbalance and implications, Atmos. Chem. Phys., 11, 13421-13449, doi:10.5194/acp-11-13421-2011, 2011.

Kaplan, A., Cane, M., Kushnir, Y., Clement, A., Blumenthal, M., and Rajagopalan, B.: Analyses of global sea surface temperature 1856-1991, J. Geophys. Res., 103, 18567-18589, 1998.

Kerr, R. A.: A North Atlantic climate pacemaker for the centuries, Science, 288, 1984-1986, 2000.

Knight, J. R., Folland, C. K., and Scaife, A. A.: Climate impacts of the Atlantic Multidecadal Oscillation, Geophys. Res. Lett., 33, L17706, doi:10.1029/2006GL026242, 2006.

Knudsen, M. F., Seidenkrantz, M.-S., Jacobsen, B. H., and Kuijpers, A.: Tracking the Atlantic Multidecadal Oscillation through the last 8,000 years, Nat. Commun., 2, 178, doi:10.1038/ncomms1186, 2011.

Lean, J. L. and Rind, D. H.: How natural and anthropogenic influences alter global and regional surface temperatures: 1889 to 2006, Geophys. Res. Lett., 35, L18701, doi:10.1029/2008GL034864, 2008.

Morice, C. P., Kennedy, J. J., Rayner, N. A., and Jones, P. D.: Quantifying uncertainties in global and regional temperature change using an ensemble of observational estimates: The HadCRUT4 dataset, J. Geophys. Res., 117, D08101, doi:10.1029/2011JD017187, 2012.

Myhre, G., Shindell, D., Breon, F., Collins, W. J., Fuglestvedt, J., Huang, J., Koch, D., Lamarque, J. F., Lee, D., Mendoza, B., Nakajima, T., Robock, A., Stephens, G. L., Takemura, T., and Zhang, H.: Anthropogenic and Natural Radiative Forcing, in: Climate Change 2013: The Physical Science Basis, Contribution of Working Group I to the Fifth Assessment Report of the Intergovernmental Panel on Climate Change, edited by: Stocker, T. F., Qin, D., Plattner, G. K., Tignor, M., Allen, S. K., Doschung, J., Nauels, A., Xia, Y., Bex, V., and Midgley, P. M., Cambridge University Press, 659-740, 2013.

Otto, A., Otto, F. E. L., Boucher, O., Church, J., Hegerl, G., Forster, P. M., Gillett, N. P., Gregory, J., Johnson, G. C., Knutti, R., Lewis, N., Lohmann, U., Marotzke, J., Myhre, G., Shindell, D., Stevens, B., and Allen, M. R.: Energy budget constraints on climate response, Nat. Geosci., 6, 415-416, doi:10.1038/ngeo1836, 2013.

Rohde, R., Muller, R. A., Jacobsen, R., Muller, E., Perlmutter, S., Rosenfeld, A., Wurtele, J., Groom, D., and Wickha, C.: A new estimate of the average earth surface land temperature spanning 1753 to 2011, Geoinf. Geostat., 1, 1, doi:10.4172/23274581.1000101, 2013.

Santer, B. D., Wigley, T. M. L., Doutriaux, C., Boyle, J. S., Hansen, J. E., Jones, P. D., Meehl, G. A., Roeckner, E., Sengupta, S., and Taylor, K. E.: Accounting for the effects of volcanoes and ENSO in comparisons of modeled and observed temperature trends, J. Geophys. Res., 106, 28033, doi:10.1029/2000JD000189, 2001.

Schlesinger, M. E. and Ramankutty, N.: An Oscillation in the Global Climate System of Period 65-70 Years, Nature, 367, 723726, 1994. 
Schmidt, G. A., Shindell, D. T., and Tsigaridis, K.: Reconciling warming trends, Nat. Gesoci., 7, 158-160, doi:10.1038/ngeo2105, 2014.

Stott, P. A., Mitchell, J. F. B., Allen, M. R., Delworth, T. L., Gregory, J. M., Meehl, G. A., and Santer, B. D.: Observational constraints on past attributable warming and predictions of future global warming, J. Climate, 19, 3055-3069, 2006.

Trenberth, K. E. and Shea, D. J.: Atlantic hurricanes and natural variability in 2005, Geophys. Res. Lett., 33, L12704, doi:10.1029/2006GL026894, 2006.

Tung, K.-K. and Zhou, J.: Using data to attribute episodes of warming and cooling in instrumental records, P. Natl. Acad. Sci., 110, 1-6, doi:10.1073/pnas.1212471110, 2013. van Oldenborgh, G. J., te Raa, L. A., Dijkstra, H. A., and Philip, S. Y.: Frequency- or amplitude-dependent effects of the Atlantic meridional overturning on the tropical Pacific Ocean, Ocean Sci., 5, 293-301, doi:10.5194/os-5-293-2009, 2009.

Zhang, R., Delworth, T. L., Sutton, R., Hodson, D. L. R., Dixon, K. W., Held, I. M., Kushnir, Y., Marshall, J., Ming, Y., Msadek, R., Robson, J., Rosati, A. J., Ting, M., and Vecchi, G. A.: Have Aerosols Caused the Observed Atlantic Multidecadal Variability?, J. Atmos. Sci., 70, 1135-1144, doi:10.1175/JAS-D-120331.1, 2013.

Zhou, J. and Tung, K.-K.: Deducing Multidecadal Anthropogenic Global Warming Trends Using Multiple Regression Analysis, J. Atmos. Sci., 70, 3-8, doi:10.1175/JAS-D-12-0208.1, 2013. 